\title{
Habitat Geology Studies on and near Georges Bank, off New England
}

\section{Introduction}

Georges Bank was once the premier East Coast fishing ground for groundfish and scallops. The decline of groundfish species due to overfishing contributed to the increasingly restrictive management of fish stocks and a need to identify and protect essential fish habitat (EFH).

Marine habitat geology is the study of the distribution of geologic materials that form the seabed, the geologic processes (such as sediment movement and deposition) that affect the seabed, and the interplay of geologic factors and species behavior that gives rise to biological habitats in general and to specific habitats deemed essential to the success of a particular species (EFH's).

\section{Management Needs}

In response to the growing need to manage fish stocks and to protect seabed environments and habitats, there is an increasing demand to know (1) the distribution of geologic materials and processes that are the framework of habitats (fig. 1), (2) the location and character of EFH's, (3) the impact of habitat disturbance by fishing gear, and (4) the processes and time periods required for the recovery of disturbed habitats.

Large areas on and near Georges Bank have been closed to fishing since December 1994 to conserve groundfish stocks (fig. 2). Sea scallops had been depleted in these areas, but they have recovered locally since 1994 . Parts of the closed areas recently have been opened for a limited time to allow scallop dredging, thus raising questions regarding the disturbance of EFH's and the bycatch of protected groundfish species.

\section{USGS Research Results}

Geologists and biologists of the U.S. Geological Survey (USGS), the National Marine Fisheries Service (NMFS) and National Marine Sanctuaries System (NMSS) of the National Oceanic and Atmospheric Administration (NOAA), the University of Rhode Island, and the University of Connecticut have been conducting joint studies of the seabed geology and biological habitats of Georges Bank for several years. These studies have shown that-

- Herring spawning sites are located on gravel bottom only where currents are strongest

- Juvenile cod survive best on gravel habitat, especially where sponges, tube worms, and other attached species (known as epifauna) increase the complexity of the seabed (fig. 1A)

- Attached species are not able to colonize gravel habitat that is buried occasionally by moving sand

- Dredging and trawling on gravel habitat remove epifauna and decrease habitat complexity, but fishing gear apparently has less long-term impact on sand habitat, especially where sand is moved by bottom currents

- Scallops prefer habitats of gravel and nonmoving sand (weak bottom currents)

- Closure of large areas to fishing allowed depleted sea scallop populations to increase markedly in 4-6 years

- Some sand-dwelling flounder species possibly prefer moving sand (strong bottom currents), but others prefer nonmoving sand habitats

These results are being used by the New England Fishery Management Council (NEFMC) and the NMFS in deciding where fishing may occur and where the seabed must be closed to fishing to protect fish stocks and habitats.

\section{Seabed Mapping}

The absence of maps showing the geology and habitat character of the seabed is the greatest single obstacle to the gathering of information required for the informed and successful management of the region's seabed habitats. The USGS has used multibeam sonar technology to map part of Closed Area I in the Great South Channel region (figs. 2, 3). The habitat information provided by these multibeam sonar images of the seabed has been used by the NEFMC to make management decisions that opened some parts of Closed Area I to scallop dredging and protected other parts that are valued as groundfish habitat.

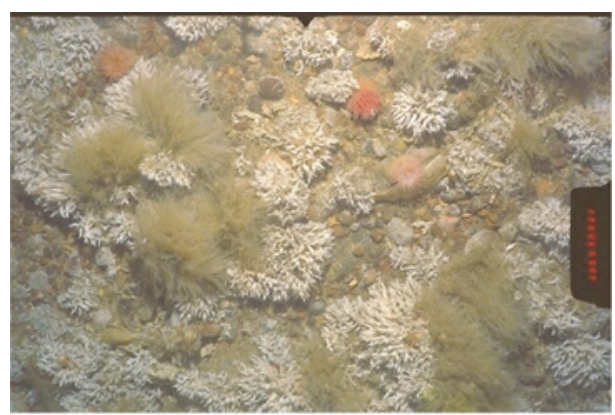

A

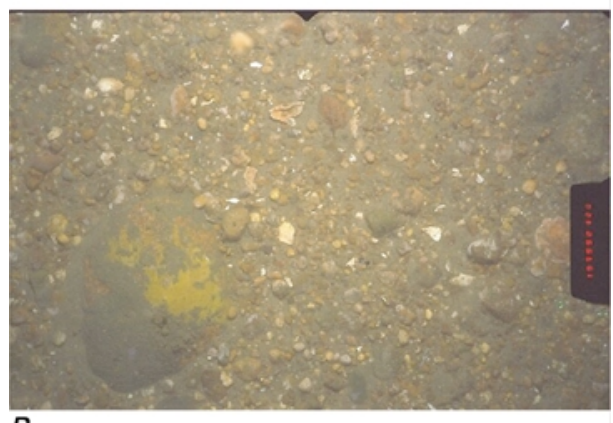

B

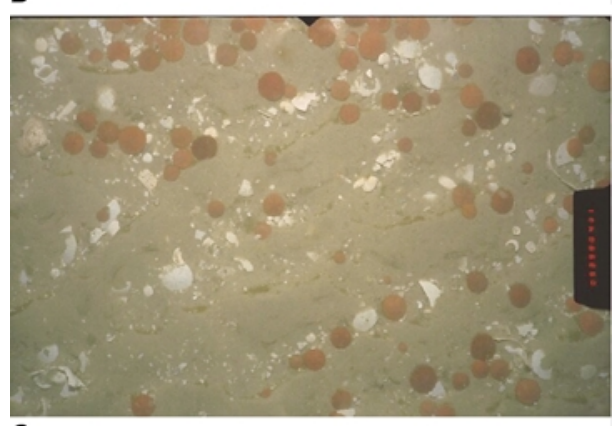

C

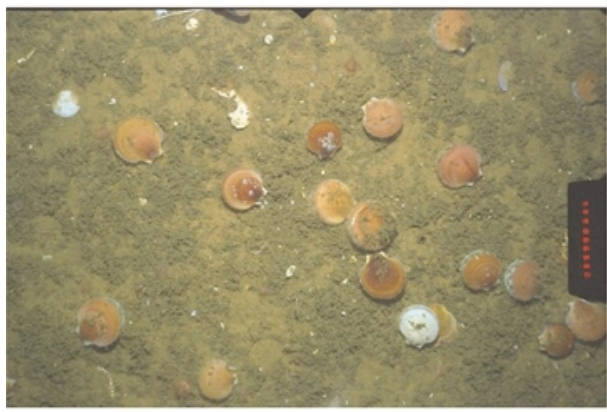

D

Figure 1. Photographs of the seabed showing some typical Georges Bank habitats. See figure 2 for locations. $A$, Undisturbed gravel habitat with epifauna of tube worms and other attached species. $B$, Gravel habitat disturbed by scallop dredges and lacking epifauna.

$C$, Moving sand habitat (strong bottom currents) with sand dollars in ripple troughs. $D$, Nonmoving sand habitat (weak currents) with sea scallops. 


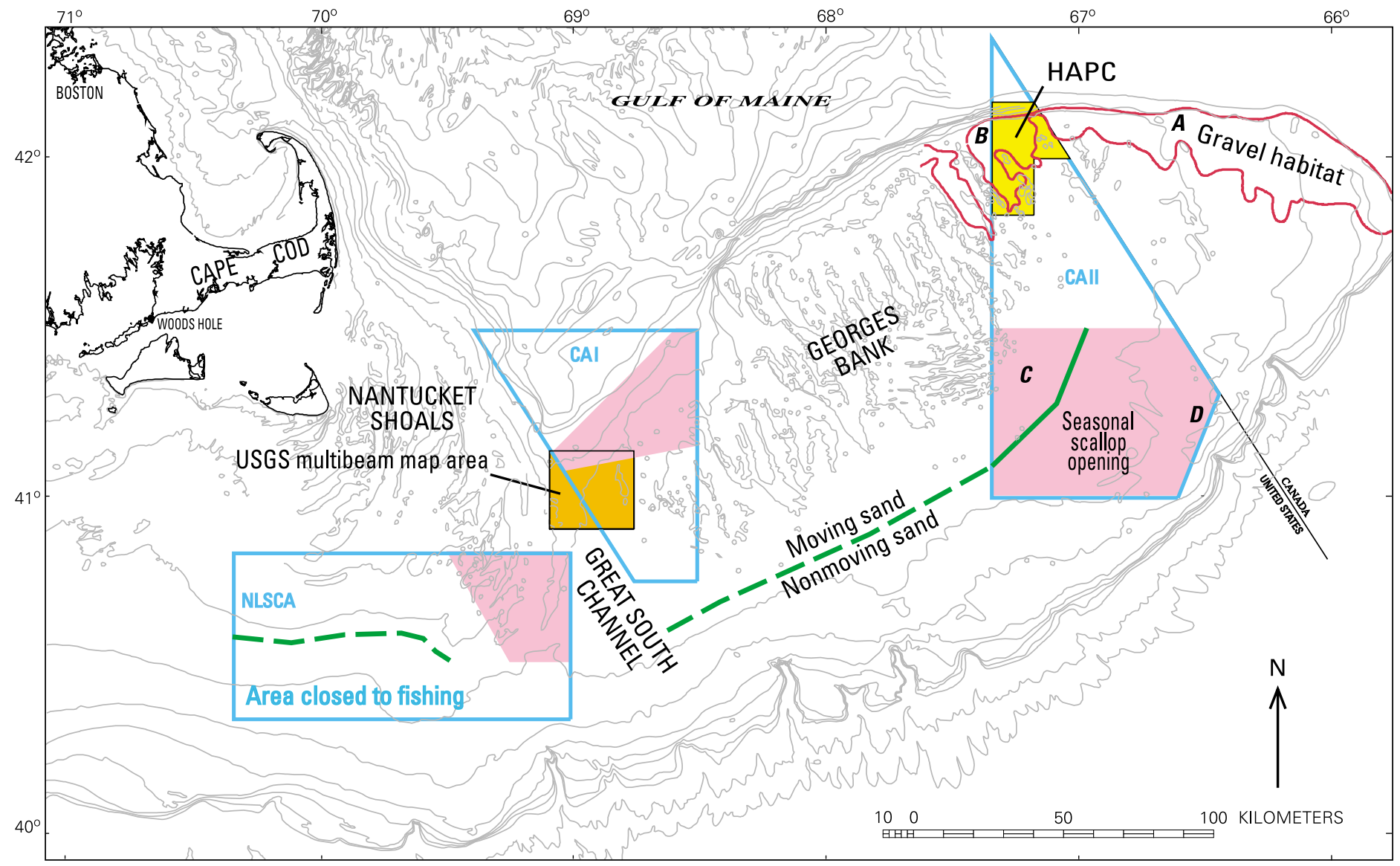

Figure 2. Map of Georges Bank and nearby regions showing areas closed to fishing since December 1994 (CAI, CAll, NLSCA), parts of closed areas that were opened seasonally to scallop dredging (pink), part of Great South Channel mapped by USGS multibeam sonar (orange; see fig. 3), gravel habitat on the northern edge of the bank (red outlines), a habitat area of particular concern (HAPC, yellow) recognized for juvenile cod, boundary (green line, dashed where inferred) between moving sand habitat (strong bottom currents) and nonmoving sand habitat (weak currents), and locations of habitats shown in figure $1(A, B, C$, and $D$ ). Base map from NOAA's National Ocean Survey Chart 13200.

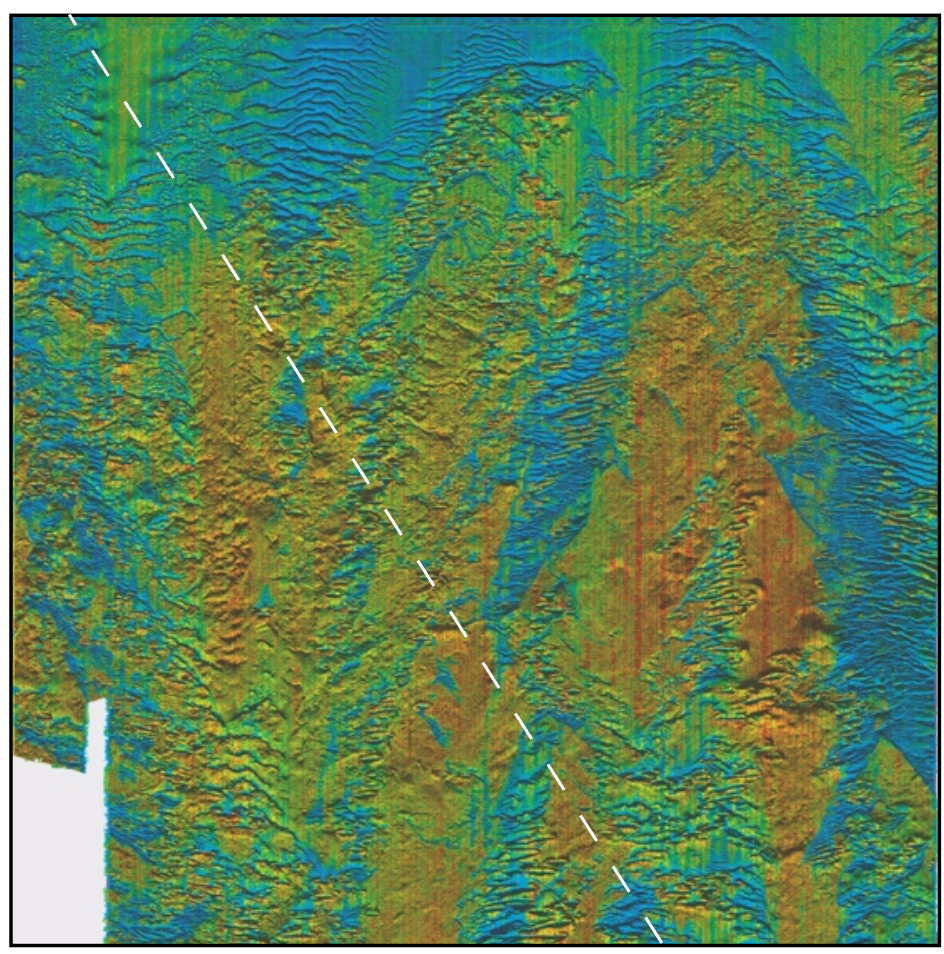

Figure 3. Part of Great South Channel (fig. 2) showing backscatter intensity draped over shaded-relief imagery of the seabed. Colors of backscatter data derived from multibeam sonar mapping indicate the wide variety of habitats in this important fishing ground: orange indicates high-backscatter material (coarse sand and gravel); green indicates moderate-backscatter material (sand); and blue indicates low-backscatter material (fine sand). Closed Area I (CAI) boundary is white dashed line. Area shown is $26 \times 26$ kilometers.

For more information, please contact:

Page C. Valentine

U.S. Geological Survey

384 Woods Hole Road

Woods Hole, MA 02543-1598

Telephone: (508) 457-2239

E-mail: pvalentine@usgs.gov 